\title{
Environmental issues raised during Moscow electoral campaigns (2013 - 2019)
}

\author{
Igor Andreev ${ }^{1}$ * \\ ${ }^{1}$ National research Moscow State University of Civil Engineering, Yaroslavskoye sh. 26, \\ Moscow, 129337, Russia
}

\begin{abstract}
The report analyzes the positions of the main political parties of Russia on the content, causes and ways to overcome the environmental problems of the capital region. During the discussions preceding the elections of Moscow authorities in 2013-2019, political parties and their candidates pointed to such acute environmental problems as air pollution, lack of adequate technologies for processing household waste, degradation of water bodies, reduction of green space. The author draws attention to the difference in the methods of coverage of environmental issues by Progovernment and opposition candidates. Pro-governmental candidates sought to draw the attention of the citizens to the obvious positive results of their previous activities and plans for future. However, these seemingly trivial approaches were based on a very detailed long-term urban strategy of the New environmental policy adopted by the government of Moscow in 2014 and designed for the period up to 2030. Opposition candidates emphasized the extreme severity of environmental problems, harshly criticized the environmental policy of the city administration, tried to identify social and class groups that impede the implementation of effective environmental measures. As a result, the positive proposals of the opposition were more «multidimensional», including several measures to rationalize and democratize the decision-making process in the environmental sphere and to undermine the capacity of social agents who prevented overcoming the environmental crisis in the capital.
\end{abstract}

\section{Introduction}

Cities, and especially megacities, are the main source of environmental pollution. At the same time, large-scale environmental projects are initiated in cities, and mass «green» movements are launched. Various forms of environmental initiatives reflect the growing concern of urban residents about their living and working conditions, prospects for their health and self-realization.

Therefore, it is quite natural that political parties seek to articulate environmental concerns and citizens' wishes in a format that is beneficial to them and then enlist their support during the election campaigns. And the theory of political parties faces the task of determining the role and place of environmental requirements in the programs of political

* Corresponding author: andreev-i-v@yandex.ru 
parties, technologies of coordination of the environmental «agenda» with the party slogans in the political, social-economic, urban planning, and other spheres of public life.

A great contribution to this task can be made by studying the environmental aspects of the inter-party controversy on the eve of the elections of the Moscow city authorities in recent years. Moscow itself is of great interest to urbanists, environmentalists, and political scientists. 12-million, rapidly developing metropolis, which is the core of the 17-million urban agglomeration, is facing a wide range of environmental problems caused by industrial activity, huge car traffic, degradation of water bodies, reduction of green space, and huge volumes of household waste. In the capital, there are strong political parties of different orientations - from left to center-right offering their projects for improving the environment. In Moscow, the same as in most of the Russian cities, such parties as Yedinaya Rossiya (United Russia), Communist Party of the Russian Federation (KPRF), Yabloko, Spravedlivaya Rossiya (Fair Russia), and LDPR (Liberal-Democratic Party of Russia) has been leading the way of the interparty discussions. An exception was an electoral campaign, preceded the elections to the Moscow City Duma 2019 when the members of Yedinaya Rossiya considered it as more advantageous to be self-nominated candidates rather than represent their party. However, the above-listed (the same as other less influential) parties did not limit themselves to the articulation of their urbanistic concepts during the pre-election time. They influenced the passage of draft laws on urban issues to the State Duma of the Russian Federation and the Moscow City Duma, initiated new forms of communication between the population and party and political structures, tried to direct the rally activity of residents of the capital.

The purpose of our study is to clarify the content, place, and role of environmental issues in the election programs of political parties that fought for representation in the Moscow authorities in 2013-2019. To achieve this goal, we propose to find out as follows:

1. characteristics of environmental problems considered by the political parties as the most relevant and politically significant;

2. the political parties' assessment of the social, administrative and technological reasons for the current environmental situation in Moscow;

3. the main activities to minimize the environmental problems presented in the election programs;

4. the measure of the importance of the party environmental guidelines for the success of political parties in elections;

5. prospects for reaching a consensus on environmental issues between the various party factions of the Moscow City Duma elected in September 2019.

The author found valuable material on various aspects of urban environmental policy in works by A. M. Bento, M. R. Jacobsen, A. A. Liu [1], C. Brunel [2], O. C. Dincer, P. G. Fredriksson [3], S. Goulden, M. Negev, S. Reicher, T. Berman [4], N. Harring [5], H. Runhaar [6]. At the same time, it should be noted that there are no analytical publications directly on the topic of this report.

\section{Methods}

The author used the observation method when attending the rallies dedicated to the discussion on environmental issues, and conducted a series of interviews with their participants. The author studied the documentary sources, such as environmental strategy of Moscow until 2030, annual reports of the mayor of Moscow Sergey Sobyanin on the results of the government of Moscow, reports of the government of Moscow on the state of the environment in Moscow in 2010 and 2014, as well as the documents of the political parties and public organizations. 


\section{Results}

There are two electoral cycles that have taken place in Moscow in recent years: the 20132014 cycle and the 2018-2019 cycle. Moscow mayoral elections were held in 2013 and 2018, and Moscow city Duma elections were held in 2014 and 2019. The environmental programs of the candidates from the respective parties in each cycle are quite similar, which makes it possible to consider them in the next two sections of this report.

\subsection{Eltctoral cycle 2013-2014}

The status of the leading political force in Moscow entrusts Yedinaya Rossiya with the main responsibility for the environmental situation in the capital. But this status also allows the party to use rather significant Moscow's financial resources to implement its course of development of the city, including the preservation and improvement of the environment. The competitive advantage of Yedinaya Rossiya over its political competitors, due to this circumstance, was adequately reflected in the strategy of the new environmental policy adopted by the government of Moscow in 2014 and designed for the period up to 2030 .

The document considers the specifics of Moscow as one of the largest megacities in the world, which has a significant demographic and industrial potential, generating a corresponding «carbon footprint». It notes the enormous transport burden on the environment, including the impact of the capital's air hub. Other important issues it considers are the environmental aspects of the accession of new huge territories to Moscow and the situation in connection with the reorganization of industrial zones.

The New Environmental Policy is based on the recognition of the significant role of the environment as a factor of health and quality of life. It involves the gradual reduction of the risk to the health of the citizens by preventing and limiting the environmental pollution, including the reduction of the air pollution, improving the management of urban water supply infrastructure, and improving the waste management practices of production and consumption.

The New Environmental Policy Strategy includes a variety of rather cost-intensive environmental measures.

Thus, it is proposed to move to a low-carbon economy in various industries, widely introduce green building technologies and renewable energy technologies.

A qualitative reconstruction of the transport system is planned, aimed at ensuring air purity, reducing noise and significantly reducing anthropogenic carbon dioxide emissions. To this end, it is proposed to significantly expand the use of public transport by the citizens, to transfer the bus fleet to electric motors and gas fuel. Incentive measures are planned to upgrade the fleet of personal use vehicles of higher environmental class, including electric and hybrid vehicles.

It is planned to introduce innovative environmentally friendly technologies for cleaning emissions and discharges of pollutants into the environment, reducing noise levels, cleaning soils, and restoring water bodies. The task is to significantly reduce the volume of buried and incinerated waste of production and consumption by increasing the share of recycled waste.

For these tasks not to remain good wishes, it is planned to form a system of economic mechanisms that stimulate enterprises implementing programs of environmental modernization of production.

The Strategy of the New Environmental Policy includes some measures for the formation of citizens' environmental culture. In particular, it is planned to make environmental information as accessible as possible, to ensure «transparency» and public 
expertise of decision-making with an environmental component. The Moscow City Administration assumes responsibility for integrating environmental education into all the city programs, where it is appropriate.

Practical implementation of the considered strategy, as well as the environmental measures planned until 2010, allowed achieving some significant goals. Thus, since 2004, the capital being ahead of the other Russian cities gradually introduces more stringent requirements for the sold motor fuel. Currently, Moscow is the only subject of the Russian Federation, having implemented the automated emission control of large industrial enterprises in its territory. For more than 10 years, the city has been operating a unified system of environmental monitoring based on automated methods of environmental control, and in 2010, for the first time in Russia, it organized the online air data monitoring and opened the access to it on the internet. The entire heat and power complex of Moscow operates mainly on natural gas - the most environmentally friendly type of fuel in terms of emissions of both pollutants and greenhouse gases. Moscow is one of the greenest megacities in the world, it has created a network of specially protected natural areas, thanks to which it was possible to preserve natural ecosystems in the dynamic development of the urban economy.

During the 2013 election campaign, Sergey Sobyanin's «7 Priorities» program reflected the environmental issues within the second priority - «Comfortable City: The Formation of a New Quality of the Urban Environment». Parks, squares and natural areas were designated in the program as «the unique wealth of the city», which is «the main resource for creating a quality urban environment». The Mayor informed the voters that over the past 2.5 years of his governing, about 50 city parks were put in order. Sergey Sobyanin promised to Muscovites to ensure approximately the same number of «public parks» in 2013. For 2014 and subsequent years, the Mayor noted, it is planned to create several new parks of the «world class» (Zaryadye Park, parks in Nagatino, Mnevniki and in the territory of New Moscow).

Notably, in this program, Sergey Sobyanin stressed the importance of considering public opinion in the conduct of environmental activities: he stated that the projects on the beautification of the city parks will be developed by the municipal administration «according to the wishes of Muscovites».

Of course, the assessments of the environmental situation in Moscow given by the opposition candidates were much more critical.

Thus, the candidate for the position of mayor of Moscow from the Spravedlivaya Rossiya Party in 2013 Nikolay Levichev described in detail the «colossal harm» caused, in his opinion, by the Moscow industrial enterprises. According to Levichev, only $60 \%$ of the Moscow industrial enterprises conduct partial cleaning of emissions. Within the city, there are more than 70 industrial zones, a dozen TPP, more than 60 district and compartment heating stations and over 1 thousand boilers. In 2013, Nikolay Levichev emphasized the importance of the problem of waste disposal, which was overlooked in the election program of the Mayor. He noted that every year the city generates more than 5 million tons of waste. While the Moscow incinerators have been obsolete, the suburban solid waste landfill is practically exhausted, and the waste dumps are full.

Nikolay Levichev also noted the alarming situation with water supply, especially in the territory of New Moscow. Muscovites still cannot safely drink tap water, as is customary in the developed cities around the world.

The result of this trouble, as stated by Nikolay Levichev, is an alarming situation with the quality of life and health of Muscovites. At average, $46 \mathrm{~kg}$ of harmful substances account for a citizen per year, but in some parts of the capital, this figure is much higher. More than a third of Muscovites live in conditions of environmental discomfort, and about a million people - in conditions of extreme discomfort. The city is among the «leaders» in 
the number of oncological diseases: $19 \%$ of deaths in Moscow are associated with oncology.

In the electoral cycle 2013-2014, almost identical estimations of the ecological situation in the city were contained both in the program of the candidate for the position of mayor from KPRF Ivan Mel'nikov and in the single program of the candidates from the party to the Moscow City Duma. In the first place, the Communists raised the issue of air pollution, which, in their opinion, exceeded the norm «almost 10 times». They also stressed the concern about the forest protective zone, which existed from 1935, because «it is by $75 \%$ reserved for building construction». The Communists predicted that in case of the New Moscow building-up, the necessary air streams from the southwest sector of the Moscow region will cease to arrive. While northward the Khimki forest is currently being destructed. The Communists developed the theme of quality tap war raised by Spravedlivaya Rossiya. They noted that the problem is not only in the unacceptably high discharge of industrial and household waste into the Moscow River but also in the quality of water purification. Mosvodokanal uses chlorine and its compounds for water disinfection - an outdated method, which has already been abandoned in the «developed cities» due to its high carcinogenicity. The intolerable situation with the quality of the atmosphere and water has become the main determinant of Moscow's nomination to the cities with the highest level of cancer.

In general, the Communists concluded, «Moscow is on the verge of an ecological catastrophe».

Sergey Mitrokhin, the candidate for the position of mayor of Moscow in the 2013 elections from the Yabloko Party, systematized the environmental indicators, according to which the capital is among the «worst regions of Russia». These include as follows: water quality in water bodies; content of radionuclides in the soil; quality of tap water; overall incidence and childhood malignancies; and the number of people living in sanitary protection zones.

According to Sergey Mitrokhin, the situation with one of the most important environmental indicators - the area of green spaces - is significantly deteriorating. If in the early 1990s it was $26 \mathrm{~m}^{2}$ for each Muscovite, by 2012 it was reduced to $16 \mathrm{~m}^{2}$. From 2000 to 2008 , the area of green spaces in the city decreased by more than $10 \%$ (due to the sealing construction within the existing buildings and due to the reduction of the territory of parks and other protected areas). At the same time, Sergey Mitrokhin pointed out at another reason for considering the environmental situation in the city in a broader territorial aspect, recalling that the administration of the Moscow region plans to reduce the forest protection belt of Moscow under the pretext of road construction.

A specific issue in the critical assessment of the ecological situation in Moscow by Sergey Mitrokhin (and Yabloko in general) has become a negative characteristic of the city administration's plans for the reconstruction of the parks. According to the politician, Regulation No. 342 of the Moscow Government adopted in 2012, contradicts both federal and capital laws. According to this document, all the projects on the park planning in Moscow are based on the type of documentation relating to the areas intended for development. All the city parks are threatened by «beautification» with the construction of retail outlets, laying tiles, replacing natural grass with artificial lawns, so-called «sanitary felling» of trees, etc.

Sergey Mitrokhin also drew attention to the fact that the project of construction of 200 new churches in the city adopted by the Mayor's Office, implies their construction in green areas, in the territory of boulevards, parks, squares, and cutting down trees.

Sergey Mitrokhin noted that $70 \%$ of the city is in the area of noise discomfort.

As you know, a paradoxical result of the election of the Moscow mayor 2013 was the second position of Aleksey Naval'ny, who received more than $27 \%$ of the vote. Thus, the 
nominee from the non-influential political structure «Republican Party of Russia People's Freedom Party» received more votes than the candidates from KPRF, Spravedlivaya Rossiya, Yabloko, and LDPR combined. In this report, it is possible to note one more paradox of the «Naval'ny phenomenon», which is an almost complete absence of the Moscow ecological situation assessment in his program. The politician neglected to devote neither a separate section nor any remarks in other sections to this issue. The only exception was the promise to expand the old and create new «green zones» formulated in Section «Decent Life for All».

The same as Aleksey Naval'ny, Mikhail Degtyarev, the candidate from LDPR, also did not offer a detailed analysis of the environmental situation in the metropolis but limited to stating the alarming state of the Moscow river and the high concentration of exhaust gases on city highways.

There are many similarities in the description of the causes of the environmental crisis in Moscow identified by the opposition candidates. The main thing, in their opinion, is the predatory orientation of the construction business, acting in alliance with the «interested» bureaucratic groups of the capital administration. "The wealth of nature is destroyed for the sake of the desire to knock out a profit from every centimeter of the earth,» - Ivan Melnikov said, for example. The situation in the field of ecology, as well as in other spheres of life of the metropolis, is caused, according to this politician, «by the connection of large capital and bureaucracy». The same way Nikolay Levichev accused «unscrupulous officials and businessmen». Sergey Mitrokhin put the responsibility for the capture of natural protected areas on the «building complex» and the municipal administration sympathetic to it.

In this regard, the measures proposed by the opposition to improve the environmental situation in the capital included, as a key component of their programs, the proposals to neutralize the influence of the above-mentioned social groups on the economic development of the city. At the same time, the main object of criticism was the «bureaucracy», which, according to the opposition, feels free in the conditions of underdevelopment of local self-government mechanisms. Thus, Sergey Mitrokhin proposed to reduce the «staff of officials», and to ban the rest from holding the positions in commercial structures. In case of his victory, Sergey Mitrokhin promised not to promote persons directly or indirectly related to big business. The politician also proposed to provide the local government with its financial base in the form of local taxes and the opportunity to spend money on its territory at its discretion. Nikolay Levichev also supported the idea of expanding the powers of local self-government. This politician also proposed to divide the powers of the mayor and the head of the Moscow government. The latter should be appointed by the mayor in agreement with the City Duma and deal with operational economic issues. Ivan Mel'nikov proposed to expand the competence of not only local self-government but also the highest representative body of the capital. The City Duma, in his opinion, should get more rights concerning the coordination of the candidates to the city ministers, control over the execution of the budget, and approval of targeted programs.

The opposition's proposals on the reform of the capital's construction complex represented different variations of two concepts - the idea of diversifying ownership forms and the idea of strengthening legal norms in the construction sector. Sergey Levichev and Ivan Mel'nikov advised to qualitatively strengthen the presence of the public sector in construction. Nikolay Levichev and Sergey Mitrokhin would like to revive housing and construction cooperatives, providing them with significant benefits in the spheres of crediting and land use. Ivan Mel'nikov promised the voters to take the work of design organizations and the urban planning commission of the Moscow City Architecture Committee «under strict control». 
These measures, according to the opposition, were to guarantee the successful implementation of the «new green course». The most detailed system of environmental measures was represented in the program of Sergey Mitrokhin. The main attention of the politician was paid to the issue of green «lungs» of the capital. He promised to increase the area of green spaces in the city-squares, parks, and landings. Emphasizing the importance of coordination with the administration of the Moscow Region, Sergey Mitrokhin proposed to begin the restoration of the forest park protective belt of Moscow, as well as to increase the number of protected areas in the capital and the Moscow Region. To move from incineration and disposal of solid waste at the landfills near Moscow to waste processing, the politician planned to conclude agreements with the leaders of the Moscow Region on the construction of such plants in its territory.

Sergey Mitrokhin noted the feasibility of introducing new technologies for environmental protection. In particular, he promised to achieve the reduction of carcinogens in the tap water using new technologies for water purification and the reduction of harmful emissions. The politician planned to expand the use of gas and other environmentally friendly fuels, to introduce environmentally friendly and efficient technologies of the decentralized energy supply and heat saving systems. An important point of the Yabloko leader's program was the idea of creating an environmental monitoring system that can track the main sources of physical pollution (atmospheric emissions, radiation, electromagnetic, etc.). Based on the monitoring data, different sanctions were to be applied to each pollutant up to the closure of the plant.

The environmental program of Nikolay Levichev prioritized fitting out the Moscow industrial enterprises with modern integrated pollution clean-up systems as soon as possible; while the «dirtiest» companies were suggested to be withdrawn outside the city. Nikolay Levichev put forward the task of «comprehensive improvement of the water supply system». To solve it, he proposed to carry out a comprehensive cleaning of the Moscow River and the urban water bodies.

Like Sergey Mitrokhin, Nikolay Levichev promised the voters, together with the administration of the Moscow region, to create protective green spaces in the Moscow suburbs adjacent to Moscow. As for Moscow itself, the politician proposed to pay attention to the qualitative characteristics of the traditional green spaces for the city. In his opinion, the old poplars and other trees provoking allergic reactions should be replaced with new species of trees and shrubs suitable for urban conditions.

The politician put forward the idea of concluding an agreement between the governments of Moscow and the Moscow region on cooperation in overcoming the environmental crisis. He noted that there is no alternative to this approach due to the presence of acute common problems and tasks that can be solved only by joint efforts: the preservation of forest plantations as the main source of oxygen, the fight against air and water pollution, as well as waste disposal. Nikolay Levichev emphasized environmental problems as the problems of the Moscow agglomeration - a dynamic system of economic, transport, and socio-cultural relations: «Many residents of Moscow have their vacations in the suburbs, and many residents of the suburbs work in the capital».

Summing up his proposal, Nikolay Levichev promised to Muscovites that in case of his election as the mayor of the city «all the city politics will be green! Clean city, which is easy to breathe in - this will be Moscow!».

Against the background of the extensive environmental projects presented to the voters by parties Yabloko and Spravedlivaya Rossiya in the electoral cycle 2013-2014, the approaches of KPRF looked meager. Tellingly, among them, there were no considerations about limiting the harmful effects of industrial enterprises. This is not surprising considering the strategic lines of the communists in the revival of the Moscow industrial complex (it was assumed, in particular, in the next 5 years, to create 2.5 million jobs in the 
«high-performance and processing industries»). The only specific proposal of KPRF in the field of environmental protection technology was the promise to introduce ultrafiltration, which is a modern harmless way of water purification. Much more attention was paid by the Communists to the legal and organizational aspects of nature protection activity optimization. They proposed, for example, to create a «department of environmental police for permanent supervision in this area», to re-approve the ban for seizure of the lands in specially protected natural areas canceled by Sobyanin's administration, to return the powers in the field of environmental protection back to the municipalities, to create a state environmental expertise and extra-budgetary environmental funds.

In the program of the candidate from LDPR Mikhail Degtyarev environmental issues were mainly reduced to the task of reclamation of the Moscow River and its banks. Degtyarev promised voters that in case of his victory, the Moscow River will be cleared, its embankments will turn into a single recreation area, the largest in Europe free municipal beach will be created near the Sparrow hills.

Based on the results of the mayoral elections 2013 in Moscow, it seems legitimate to conclude that there is no pronounced correlation between the number of votes received by the candidates (there were six in total) and the quality of their environmental programs. The opposition candidates Sergey Mitrokhin and Nikolay Levichev with their detailed, well-reasoned programs took fourth and sixth positions respectively, moreover, Levichev let take the lead to the candidate from LDPR Mikhail Degtyarev, who had not offered as we noted above, a systematic approach to the solution of environmental problems. Ivan Mel'nikov, who proposed a very concise and superficially substantiated environmental program took the third position with more votes than Sergey Mitrokhin, Mikhail Degtyarev, and Nikolay Levichev taken all together. Aleksey Naval'ny's second position was due, of course, not to his environmental agenda, which is rather meager, as we have seen, but to the image of a new bright «non-systemic» opposition politician he created an image that was at the time in demand for more than a quarter of Muscovites who came to the polls. The convincing victory of Sergey Sobyanin, who received more than $51 \%$ of the vote, was mainly due to the fact that he, unlike all other candidates, had the opportunity to remind Muscovites of his real achievements as the mayor, in the context of which his program provisions were perceived as justified extrapolations into the future of the already identified trends in the development of the metropolis. For example, seeing firsthand on the streets of Moscow an increasing number of comfortable low-floor buses and trolleybuses that meet the European environmental standards (and that time already 65 and 45 percent of the depot, respectively), the voters had no reason to doubt his ability to achieve a long-term success in solving the environmental problem in general.

A similar pattern took place the following year. The phenomenon of «a successful mayor», as well as the political weight of Yedinaya Rossiya at the time, resulted in a landslide victory of the party in the elections to the Moscow City Duma 2014. The Representatives of Yedinaya Rossiya and the self-nominated candidates supported by this party took 38 positions out of 45. KPRF that copied its last year's environmental agenda, won 5 positions. The representatives of LDPR and the Rodina Party received one position per each. None of the candidates from Yabloko and Spravedlivaya Rossiya passed to the capital's parliament.

\subsection{ELECTORAL CYCLE 2018-2019}

The orientation to the «decentralization» of the process of introducing environmental protection measures to provide more local context and involvement of the citizens in the self-government arrangements, was developed in the pre-election strategy of Sergey Sobyanin in 2018. The Mayor proposed an outside-the-box solution that required a lot of 
effort from his campaign staff and the use of «administrative resources» at the local level: he offered the voters 146 election programs (according to the number of the city's districts) instead of one. The creation of so many programs requires the collection of a vast array of specific information. And it has been achieved, in particular, based on critical comments and suggestions of the citizens: the volunteers of the Sergey Sobyanin's staff gathered about 8 thousand orders of Muscovites, 1.5 thousand of which entered the program, and over 800 were implemented already during the election campaign. At the same time, the main idea of the Mayor's election campaign was such a motto as leveling the quality of life of the citizens living in different areas, including the alignment of environmental indicators.

S. Sobyanin emphasized his practical achievements in recent years, which, in his opinion, marked the beginning of a «cardinal» improvement of the environmental situation in the capital. Moscow every year improves its indicators, despite population growth and number of cars, he claimed. The mayor expressed confidence that Moscow will become more environmentally friendly city every year.

The mayoral candidate from the KPRF Vadim Kumin, the same as Ivan Mel'nikov in the previous election campaign, complained about the almost complete destruction of the Moscow forest protection belt and promised the voters to save the «remaining forests». A new point in the program of Vadim Kumin was an appeal to the problem of garbage disposal: the politician assured citizens of his determination to eliminate spontaneous garbage dumps and to introduce modern technologies for processing and recycling of household waste. The proposals of the communists on the development of the environmental monitoring system, which had been made earlier, were concretized here: Kumin promised to create «open» environmental monitoring systems in each district. Another innovation was the idea of the politician on the introduction of a program to encourage businesses to create environmentally friendly industries.

The candidate of Spravedlivaya Rossiya Il'ya Sviridov presented a much more detailed environmental program compared to his communistic rival. Among the most acute problems of Moscow, he attributed as follows: air pollution (according to him, recently the level of the maximum permissible concentration of hydrogen sulfide in the south and south-west of the capital has been repeatedly exceeded 19-50 times); irrational development of green areas; the situation with the collection and disposal of garbage; and the inhumane attitude to homeless animals. Unlike Vadim Kumin, Il'ya Sviridov did not limit himself to the promise to preserve the existing green areas but promised the voters to «multiply» the area of green spaces and to restore the destroyed areas. It is noteworthy that $\mathrm{Il}^{\prime}$ ya Sviridov «came down» to the level of «urban ecocide» perceived by the citizens, guaranteeing them his support in their just struggle against the practice of urban and municipal administrations' costly and harmful activities - mowing the grass on lawns, removal of leaves, and use of hazardous chemicals in residential areas in winter. To solve most of these problems, the politician proposed to adopt special city programs. His proposal to achieve the removal of the Moscow oil refinery in Kapotnya from the city and the closure of incinerator No. 4 in Nekrasovka was extremely specific.

Il'ya Sviridov, in our opinion, revealed the «agglomeration» aspects of the environmental problem in the most detail compared to other candidates. In particular, he stated that the responsibility for the building-up and felling of the forest protection area of Moscow is borne by the Moscow region. The Moscow region administration does not prevent the construction of housing in the water protection area of the rivers, which are a source of drinking water for the capital. Of course, the politician did not deny Moscow's responsibility for the removal of garbage «in huge volumes» to the regional landfills of solid waste, which worsens the environmental situation in the region. According to Ilya Sviridov, the dangerous growth of these problems is facilitated by the actual lack of 
coordination in the environmental sphere between the administrations of Moscow and the Moscow region. As a priority measure to establish this coordination, he proposed to introduce the position of vice-mayor in the Government of Moscow for cooperation with the Moscow region, who will only deal with complex issues related to the life of the agglomeration. Il'ya Sviridov also proposed preventing the attempts of residential building on the adjacent territories of Moscow, if it affects the position of the Muscovites; strengthening the work on introduction of separate waste collection in the capital; developing a strategy that will allow refusing the storage of garbage in the landfills and its incineration together with the region; and stopping the felling of the Moscow forest protection belt and beginning its restoration together with the region.

LDPR candidate Mikhail Degtyarev, in contrast to his 2013 program, included a special section «Ecology and recreation» in his program. The thesis of the Moscow River as «the main recreational resource of the capital» again appeared in the new program. But now it appeared and the requirement to «create continuous green areas» from the borders of Moscow to its center, partially recreate the gardens and boulevards on the Garden ring. Degtyarev's new thesis was the development of a program to reduce the noise level in all areas of Moscow.

The representative of the party «Yabloko» in the mayoral elections in 2018 did not participate.

It is difficult to explain the convincing victory of S. Sobyanin, who gained over $70 \%$ of the votes, only by the absence in the election race of a bright representative of the «nonsystemic» opposition, such as A. Naval'ny. (Results of other candidates: V. Kumin $11,38 \%$, I. Sviridov $-7,01 \%$, M. Degtyarev $-6,72 \%$, M. Balakin $-1,87 \%$ ). The main reason for the success of the mayor was further strengthening his image as a «tough boss» of the city, including the implementation of environmental projects (creating Europe's largest fleet of electric buses, reconstruction of recreation areas, launch of the housing renovation program, which includes guarantees of environmentally sound technologies for demolition of old houses, etc.).

The results of the September 2019 elections to the Moscow city Duma were seriously influenced by national political trends related to the reform of the social sphere and the tax system. However, the main opposition «players» in the capital's political field have modernized not only the socio-political slogans, but also the environmental sections of their election programs.

Thus, the Communists have repeatedly increased the range of their environmental requirements, bringing their number to 16 (compared to 4-5 in the election cycle of 20132014). At the same time, the problem of garbage disposal, which was not mentioned at all earlier, was mentioned as the central one; to solve it, the Communists formulated 5 proposals. Other proposals include: encouraging businesses to introduce environmentally friendly industries, along with economic sanctions against enterprises that pollute the environment; removal of particularly polluting businesses from residential areas; abandonment of residential development and the creation of industrial enterprises in the «green» areas of the city; creation of a public environmental monitoring system in each district of the city; introduction of environmental education programs for citizens in all information resources of the city government.

It seems to us that this program marks a decisive turn of the Moscow Communists to environmental issues as one of the priorities in their activities.

At the same time, the party "Yabloko», on the contrary, formulated a list of its environmental requirements in a very concise form, probably believing that it will facilitate their perception by voters. The party called for an end to the endless development that would eventually turn Moscow into a «garden city»; for the adoption of 
a series of laws that protect the purity of air, water, drinking water, as well as to solve the problem of disposal of household and industrial waste.

Some candidates from Spravedlivaya Rossiya have chosen a similar way of broadcasting their environmental requirements to voters. Thus, Mikhail Timonov, who won the elections, formulated in his Manifesto only two key requirements: to preserve the green areas of the city, to categorically prohibit the construction of capital structures in parks and squares; to stop poisoning the city with reagents, to use only modern and environmentally friendly ways of cleaning roads.

The result of the elections to the Moscow city Duma was the relative success of the opposition, which received 20 seats (Communists -13 , the party Yabloko -4 and Spravedlivaya Rossiya - 3).

\section{Discussion}

Speaking with scientific reports on the subject, the author received recommendations from his colleagues to explore deeper the relationship between the environmental programs of political parties and their ideological orientations. In addition, colleagues recommended the author to explore the general and specific aspects of the inter-party struggle on environmental issues in the context of international experience. The author considers these recommendations worthy of attention and will try to take them into account in his further work on this topic.

\section{Conclusions}

The political forces competing in the Moscow elections did not consider their environmental concepts as a factor of significant importance for attracting votes. This is particularly evidenced by the fact that the environmental sections tended to be at the bottom of their programs or even absent altogether. (The only exception was Sergey Sobyanin's 2013 program, in which the environmental issues were assigned number 2 in a series of seven priorities). The voters also failed to properly evaluate the candidates who submitted sets of well-designed environmental proposals. Thus, the Communists, whose environmental agendas can be assessed as very concise, invariably outstripped the candidates from Yabloko and Spravedlivaya Rossiya with their detailed lists of environmental measures. In his turn, on the mayoral elections 2013, the Communist Ivan Melnikov let take the lead to Aleksey Navalny who had not consider it as necessary to include the special environmental section in his program.

In our opinion, this phenomenon is primarily caused by the circumstance that the Moscow voters did not believe the opposition politicians, who qualified the environmental situation in Moscow as «ecocide» (Ilya Sviridov), «the verge of ecological catastrophe» (candidates from KPRF), etc. Probably the environmental situation in the capital was not considered as extremely tragic by the drafters of the party programs either, who prioritized the suggestions in the areas of urban planning, transport, social policy, and reforms of urban governance. Eventually, the results of the Moscow elections were determined, firstly, by the prestige of the respective political party on a national scale and, secondly, by the practical results of the activities of the political forces holding the power in the capital (the effect of «strong leader» Sergey Sobyanin and «his» party - Yedinaya Rossiya). At the same time, Aleksey Naval'ny's high results in the mayoral elections 2013 and good results of Yabloko in the municipal elections 2017 were determined by «Moscow specifics» - a relatively high demand of the electorate for political forces positioning themselves as «irreconcilable» opposition. 
The technologies of broadcasting to the voters of their environmental policy orientations differed between the representatives of the «pro-governmental» and opposition parties. «Pro-governmental» candidates sought to draw the attention of the citizens to the obvious positive results of their previous activities and plans. However, these seemingly trivial approaches were based on a very detailed long-term urban strategy of the new environmental policy and systematic monitoring of the environmental situation, the results of which, incidentally, were available to the public representatives. The opposition candidates, first, sought to paint an extremely gloomy picture of the current environmental situation in the city, and second, emphasized the real and imaginary mistakes made by the administration in the environmental policy ignoring any of its achievements, and, third, sought to identify the social-class groups responsible, in their opinion, for the current alarming state of affairs. As a result, the positive proposals of the opposition were more «multidimensional», including several measures to rationalize and democratize the decision-making process in the environmental sphere and to undermine the capacity of social agents who prevented overcoming the environmental crisis in the capital.

In general, with all the costs of election battles, we must admit that for attentive, interested voters, the comparison of the arguments of competing political forces was a useful thing, contributing to the formation in their mind of a more realistic, multidimensional picture of the environmental situation in the metropolis.

Identifying the features of inter-party controversy in the election cycle 2018-2019, one may state that compared to the previous election cycle 2013-2014, there is an increase in the importance of the problem of the household and industrial waste disposal, the interaction of authorities in the framework of the Moscow agglomeration, the specific environmental situation at the district level, the search of directions for the transformation of the urban management structures to adapt the latter to new environmental challenges, and raising awareness of the citizens about the environmental situation.

The author believes that the success of opposition parties in the elections to the Moscow city Duma in September 2019 will contribute to the practical implementation of some provisions of their environmental programs.

\section{References}

1. A. M. Bento, M. R. Jacobsen, A. A. Liu, J. Envir. Econ. Manag. 90, 61-77 (2018)

2. C. Brunel, J. Envir. Manag. 248, article 109290 (2019)

3. O. C. Dincer, P. G. Fredriksson, Resour. Ener.Econ. 54, 212-225 (2018)

4. S. Goulden, M. Negev, S. Reicher, T. Berman, Environ. Sci. Pol. 98, 39-46 (2019)

5. N. Harring, Environ. Sci. Pol. 82, 1-8 (2018)

6. H. Runhaar, Environ. Imp. Asses. Review, 59, 1-9 (2016) 